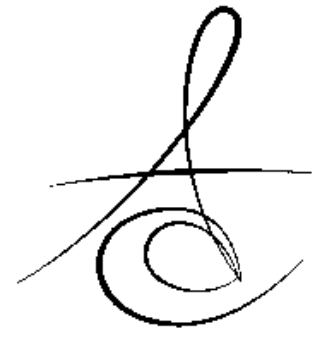

Makale Kodu/Article code: 2636

Makale Gönderilme tarihi: 22.02.2016

Kabul Tarihi: 07.04.2016

\section{ORTODONTİK TEDAVİ GÖREN HASTALARDA PERİODONTAL DURUMUN VE KÖK REZORBSİYONUNUN DEĞERLENDİRİLMESİ}

\section{ASSESSMENT OF PERIODONTAL STATUS AND ROOT RESORPTION IN ORTHODONTIC PATIENTS}

\author{
Dr.Dt. Nilsun BAĞIş* \\ Dt. Kemal Gökalp GEZER* \\ Dt. Orhan ÖZDİLER ${ }^{* *}$ \\ Dt. Aysel Ufuk ŞENOL* \\ Dt. Gökçe KILIÇ**
}

\section{öz}

Amaç: Malokluzyon periodontal sağlığı olumsuz etkileyen önemli bir faktördür ve ortodontik tedavinin amaçlarından biri bu sorunun tedavi edilerek, bireylere ideal bir dentisyon ve daha iyi dental sağlık kazandırımasıdır. Bu çalışmanın amacı, ortodontik tedavinin periodontal sağlık ve kök rezorbsiyonu ile ilişkisini değerlendirmektir.

Gereç ve Yöntem: Ortodontik tedavinin periodontal sağlık ve kök rezorbsiyonları üzerine etkisinin değerlendirildiği bu retrospektif çalışmada, Ankara Üniversitesi Dişhekimliği Fakültesi Ortodonti Anabilim Dalı'nda tedavi görmüş 101 kadın 75 erkek olmak üzere toplam 176 bireyin intra oral fotoğraf ve panoramik radyografileri değerlendirildi. Uygun kriterlere sahip 104 hastada (43 erkek, 61 kadın) görünür plak, görünür enflamasyon ve kök rezorbsiyonu varlığı kaydedildi.

Bulgular: Cinsiyetin kök rezorbsiyonu üzerine etkisi bulunmazken, ortodontik amaçla diş çekiminin tedavi süresini arttırdığı ve kök rezorbsiyonu ile ilişkili olduğu görüldü. Periodontal enflamasyon ve oral hijyen seviyesinin ortodontik tedavi ile ilişkili olduğu, sabit ortodontik tedavi gören bireylerde plak indeksi ve gingival indeksin anlamlı artış gösterdiği bulundu.

Sonuç: Ortodontik tedavi esnasında gingival sağlığın korunması açısından, hasta, ortodontist ve periodontistin iletişimi önemlidir.

Anahtar Kelimeler: Kök rezorbsiyonu, periodontal sağlık, ortodontik tedavi

\section{ABSTRACT}

Aim: Malocclusion has been shown to affect periodontal health and one of the objectives of orthodontic treatment is to promote better dental health and prolong the life of dentition. Purpose of this study, assessment of relationship between periodontal health and root resorption.

Material and Methods: This retrospective study evaluated related to root resorption and periodontal health after orthodontic treatment. A total of 176 patients among whom 101 were female and 75 were male, recruited from the Department of Orthodontics, Faculty of Dentistry, University of Ankara included in the study. Intra-oral photographs and panoramic radiographs were analyzed, and the presence or absence of visible plaque, visible inflammation, and root resorption were recorded for 104 patients (43 male, 61 female) who providing appropriate criteria.

Results: There is no relationship between root resorption after treatment with regard to gender but duration of treatment were found to be more associated with root resorption than with extractions. Positive correlation was found between oral hygiene status, periodontal inflammation and orthodontic therapy. In patients treated with fixed orthodontic appliances, plaque index and gingival index showed significant increases after treatment.

Conlusion: Considering the relationship between orthodontic treatment and gingival health, cooperation among patients, orthodontists, and periodontists is important.

Keywords: Root resorption, periodontal health, orthodontic therapy 


\section{GİRİş}

Malokluzyon periodontal sağlığı olumsuz etkileyen önemli bir faktördür ve bu durum ortodontik tedaviyle çözümlenerek bireylere ideal bir dentisyon sağlanabilir. Böylelikle kolay temizlenebilir alanlar yaratılarak diş/diş eti sağlığı korunabilir; ancak klinisyen, ortodontik tedavinin periodontal dokular üzerinde olumsuz etkileri olabileceğini unutmamalıdır. ${ }^{1}$ Oral kavite zengin bir ekosisteme sahiptir ve plak bakterileri periodontal hastalığın başlaması ve ilerlemesinde en önemli faktördür. Çeşitli faktörler oral ekolojik denge üzerinde etkili olabilir ve mekanik temizliğin etkin yapılamaması sonucu periodontal hastalık gelişebilir. ${ }^{2-5}$

Ortodontik tedavi, iskeletsel ve dental problemleri çözümlemeyi hedeflese de, hasta ağzında kulIanılan apareyler ekosistemi bozabilir ve oral hijyen alışkanlıklarında farklııklara yol açabilir. Ortodontik gerekçe ile uygulanan çeşitli cerrahi uygulamalara bağı (gingivektomi, diş çekimi, mini implant...v.s.) iyileşme prosedürü mekanik temizliğin aksamasına neden olabilir. Ek olarak, mekanik prosedür içerisinde uygulanan kuvvetler yumuşak dokuda reaksiyona neden olabildiği gibi dişlerde de kök rezorbsiyonlarına neden olabilir. Kök rezorbsiyonu; enflamatuar durum, travma veya asemptomatik faktörlere bağlı görülebileceği gibi sıklıkla ortodontik tedavilerin bir komplikasyonu olarak da karşımıza çıkabilir. ${ }^{6-8}$

Bu çalışmanın amacl, ortodontik tedavi görmüş bir grup bireyde, ortodontik tedavi ile periodontal sağlık arasındaki ilişkiyi değerlendirmek, ortodontik tedavi prosedürlerinin kök rezorbsiyonu, tedavi süresi ve periodontal duruma etkisini incelemektir.

\section{GEREÇ VE YÖNTEM}

Çalışmamızın materyalini Ankara Üniversitesi Diş Hekimliği Fakültesi Ortodonti Anabilim Dalı Kliniği'nde 2011-2015 yılları arasında tedavi görmüş toplam 176 birey oluşturmuştur. Klinik ve radyolojik değerlendirmeler için, hastaların tedavi öncesi ve sonrası panoramik radyografileri ile klinik fotoğrafları kullanılmıştır. Bunların arasında, ortognatik cerrahi görmüş veya dudak damak yarığı olan bireyler, sistemik rahatsızlığı veya düzenli ilaç kullanımı olanlar ile kayıtlarında eksiklik bulunan, değerlendirmenin mümkün olmadığı görüntüye sahip bireyler çalışma dışı bırakılmıştır. Sonuç olarak, 18 yaşından küçük, minimum 12 ay sabit ortodontik tedavi görmüş (herhangi bir ek plak vs kullanmamış) toplam 104 hasta (43 erkek, 61 kadın) çalışmamızın materyalini oluşturmuştur. Radyolojik incelemede maksiller ve mandibular kesiciler, kanin, 1 . ve 2 . premolarlar ve 1. molarlar değerlendirmeye alınmış, kök rezorbsiyon skorlaması modifiye kök rezorbsiyon sınıflamasına göre yapılmıştır (Şekil 1). ${ }^{9}$

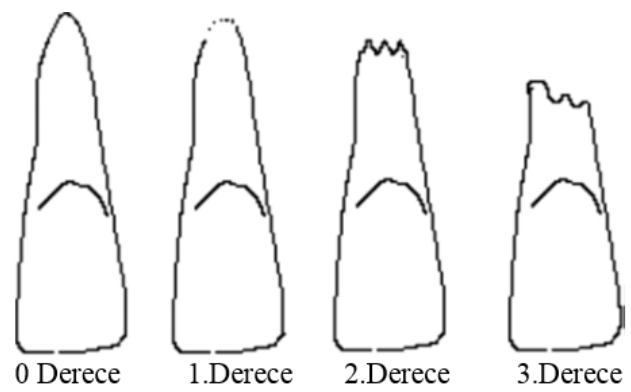

Şekil 1. Modifiye kök rezorbsiyonu sınıflandırma yöntemi. 0 Derece: Görülebilen rezorbsiyon yok. 1. Derece: Kök apeksinde hafif rezorbsiyon, silikleşme. 2. Derece: orta düzey rezorbsiyon kök apeksi izlenemez, düzensiz kontur alanı, rezorbsiyon miktarı kökün $1 / 4^{\prime}$ ini aşmamış. 3 . Derece: şiddetli rezorbsiyon, düzensiz kontur alanı, rezorbsiyon miktarı kök boyunun $1 / 4^{\prime}$ ini aşmış.

Skorlandırma, tedavi sonrası panoramik radyograflar üzerinde yapılmış ancak kök kapanmasının gerçekleşmemiş olması veya kök morfolojisinden doğabilecek farklııkları elimine etmek amacıyla tedavi öncesi panoramik radyografilerle karşılaştırma yapılmıştır. Değerlendirme tek bir klinisyen tarafından (G.G.) karanlık ortamda gerçekleştirilmiş, değerlendirme öncesi araştırıcı rastgele seçilen 15 hasta panoramik radyografını 10 gün ara ile değerlendirmiş, her iki değerlendirme paired Wilcoxon test ile karşılaştırılmıştır. Ölçümler arasındaki fark anlamlı çıkmamıştır. Daha sonra her hasta için üst anterior ve posterior ile alt anterior ve posterior dişler için ortalama kök rezorbsiyon miktarı hesaplanmıştır. ${ }^{10}$ Periodontal durumun değerlendirilmesi, tedavi öncesi ve sonrası sagittal ve frontal açıdan çekilmiş intra-oral dijital fotoğraflarda görünür plak ve enflamasyon düzeyi, 11 yıllık deneyimli periodontolog tarafından (N.B.) benzer şekilde kalibre olarak, karanlık ortamda ve aynı bilgisayar ekranında gerçekleştirilmiştir. Maksiller ve mandibular kesiciler, kanin, 1. ve 2. premolarlar ve 1. molarlar değerlendirmeye alınmış, her dişin bukkaldistal-mesial yüzeyleri için görünür plak ve enflamasyon düzeyi skorlanmıştır. ${ }^{11,12}$ 
Ek olarak, bireylerin demografik bilgileri, yaş, cinsiyet, tedavi süresi ve tedavide çekim uygulanıp uygulanmadığı kaydedilmiştir.

\section{Istatistiksel analiz}

Tüm veriler SPSS 20.0 for Windows programında değerlendirilmiştir. Çalışmamızda popülasyon farklı gruplara ayrımış (cinsiyet, diş çekimi) ve bu grupların ortalama kök rezorbsiyon skoru ile ilişkisi Student's t-testi ile değerlendirilmiştir. Diş çekimi ile demografik değişken ve tedavi süresi arasındaki ilişki bivaryant korelasyon analizi kullanılarak değerlendirilmiştir. Periodontal durum değerlendirmesine gruplara bağlı aritmetik ortalama skor Student's t-testi ile, istatistiksel farklılıklar Mann-Whitney U-testi ile hesaplanmıştır.

\section{BULGULAR}

Çalışmamızda Ankara Üniversitesi Dişhekimliği Fakültesi Ortodonti Anabilim Dalı Kliniğinde 2011-2015 yılları arasında tedavi görmüş toplam 176 bireyin kayıtları taranmış ve 104 birey araştırmaya dahil edilmiştir (43 erkek, 61 kadın). Bireylerin yaş ortalaması $13,77 \pm 9,01$ ve tedavi süresi ortalaması $30,44 \pm$ $12,86^{\prime}$ dır. İncelenen 2912 dişin $71^{\prime} i(\% 2,43)$ ortodontik endikasyon nedeniyle çekilmiştir. Çalışma popülasyonunun 23'üne $(\% 22,11)$ tedavi sırasında diş çekimi uygulanmış, $81(\% 77,89)$ bireyin tedavisi diş çekimi yapılmadan bitirilmiştir ve bu fark anlamlı bulunmuştur $(p<0,05)$. Diş çekimi uygulanan bireylerin tedavi süresi, çekim uygulanmayan bireylere oranla anlamlı derecede yüksek bulunmuştur $(p<0,05)$ (Tablo 1$)$.

Tablo 1. Ortodontik amaçla diş çekimi uygulamasının cinsiyet ve ortodontik tedavi süresiyle ilişkisi

\begin{tabular}{|c|c|c|c|c|c|c|c|}
\hline Diş çekimi & Kadın & Erkek & p & Toplam & p & $\begin{array}{c}\text { Tedavi } \\
\text { süresi (Ay) }\end{array}$ & p \\
\hline Evet & 17 & 6 & ${ }^{*} \mathrm{p}<0,05$ & 23 & \multirow{2}{*}{$* \mathrm{P}<0,05$} & $35,34 \pm 12,56$ & \multirow{2}{*}{$*_{p}<0,05$} \\
\hline Hayır & 44 & 37 & 0,258 & 81 & & $\begin{array}{c}29,04 \pm 9 \\
86\end{array}$ & \\
\hline
\end{tabular}

Her birey için tedavi sonrasında ortalama kök rezorbsiyon skoru varlığı değerlendirildiğinde, genel populasyon için cinsiyetler arası fark gözlenmezken $(p=0,095)$, tedavisi sırasında diş çekimi yapılan bireylerdeki ortalama kök rezorbsiyon skorunun anlamlı olarak yüksek olduğu görülmüştür $(p<0,05)$. Lokalizasyonuna göre ortalama kök rezorbsiyonlarının diş çekimi ve cinsiyete göre ilişkisi incelendiğinde, yalnızca maksiller posterior bölgede ortalama kök rezobsiyon miktarının diş çekimi yapılan bireylerde artmış olduğu $(p<0,05)$, diğer gruplarda istatistiksel farklılık bulunmadığı saptanmıştır (Tablo 2).

Bireylerin periodontal durumuna ilişkin plak ve gingival enflamasyon skoru ortalamaları Tablo 3'de gösterilmiştir. Ortodontik tedavi sonrası hastaların hiç birinde gingival çekilme gözlenmemiştir.

Tablo 2. Kök rezorbsiyonu miktarının lokalizasyonlara göre dağılımı

\begin{tabular}{|c|c|c|c|c|c|}
\hline \multicolumn{7}{|c|}{ Ortalama Kök Rezorbsiyon Miktarı } \\
\hline & $\begin{array}{c}\text { Maksiller } \\
\text { Anterior }\end{array}$ & $\begin{array}{c}\text { Maksiller } \\
\text { Posterior }\end{array}$ & $\begin{array}{c}\text { Mandibular } \\
\text { Anterior }\end{array}$ & $\begin{array}{c}\text { Mandibular } \\
\text { Posterior }\end{array}$ & Total \\
\hline $\begin{array}{c}\text { Diş çekimi } \\
\text { Evet }(n=23)\end{array}$ & 1,02 & 0,44 & 0,53 & 0,31 & 0,58 \\
Hayır $(n=81)$ & 0,39 & 0,05 & 0,46 & 0,10 & 0,25 \\
\hline $\boldsymbol{p}$ & 0,098 & $*<0,05$ & 0,262 & 0,189 & $*<0,05$ \\
\hline $\begin{array}{c}\text { Cinsiyet } \\
\text { Erkek } \\
(n=43) \\
\text { Kadın } \\
(n=61)\end{array}$ & 0,44 & 0,10 & 0,44 & 0,15 & 0,28 \\
\hline $\boldsymbol{p}$ & 0,60 & 0,16 & 0,49 & 0,14 & 0,35 \\
\hline \multicolumn{7}{|l|}{} & 0,155 & 0,259 & 0,162 & 0,155 & 0,095 \\
\hline
\end{tabular}

Tablo 3. Tedavi öncesi ve sonrası periodontal parametrelerin gruplara göre dağııımı

\begin{tabular}{|c|c|c|c|c|c|c|}
\hline & \multicolumn{3}{|c|}{$\begin{array}{l}\text { Plak İndeks } \\
\text { Ortalaması }\end{array}$} & \multicolumn{3}{|c|}{$\begin{array}{c}\text { Gingival İndeks } \\
\text { Ortalaması }\end{array}$} \\
\hline & $\begin{array}{l}\text { Tedavi } \\
\text { öncesi }\end{array}$ & $\begin{array}{l}\text { Tedavi } \\
\text { sonrası }\end{array}$ & & $\begin{array}{l}\text { Tedavi } \\
\text { öncesi }\end{array}$ & $\begin{array}{l}\text { Ted } \\
\text { sonr }\end{array}$ & $\begin{array}{ll}\text { vi } & \text { p } \\
\text { SI } & \end{array}$ \\
\hline $\begin{array}{l}\text { Diş çekimi } \\
\text { Evet }(n=23) \\
\text { Hayır }(n=81)\end{array}$ & $\begin{array}{l}0,59 \\
1,10\end{array}$ & $\begin{array}{l}0,85 \\
0,86\end{array}$ & $\begin{array}{l}0,185 \\
0,077\end{array}$ & $\begin{array}{l}1,56 \\
1,55\end{array}$ & $\begin{array}{l}1,99 \\
1,72\end{array}$ & $\begin{array}{c}* p<0,05 \\
0,241\end{array}$ \\
\hline $\begin{array}{l}\text { Cinsiyet } \\
\text { Erkek }(n=43) \\
\text { Kadın }(n=61)\end{array}$ & $\begin{array}{l}0,56 \\
0,94\end{array}$ & $\begin{array}{l}0,84 \\
1,12\end{array}$ & $\begin{array}{c}0,321 \\
0,328\end{array}$ & $\begin{array}{l}0,98 \\
1,16\end{array}$ & $\begin{array}{l}1,12 \\
1,17\end{array}$ & $\begin{array}{l}0,251 \\
0,781\end{array}$ \\
\hline Total $n=104$ ) & 0,86 & 2,01 & $<0,05$ & 1,82 & 1,86 & 0,341 \\
\hline
\end{tabular}

\section{TARTIŞMA}

Ortodontik tedavi gören bireylerde, kök rezorbsiyonu ve periodontal durumun, panoramik radyografiler ve klinik fotoğraflar kullanılarak değerlendirilmesinin amaçlandığı bu çalışmada, çalışma popülasyonunun \%22,11'inde ortodontik endikasyon nedeniyle diş çekimi yapılmıştır. Ve diş çekimi uygulamasının ortodontik tedavi sürecini istatistiksel olarak anlamlı derecede arttırdığı görülmüştür $(p<0,05)$. Bu bilgi ortodontik tedavi esnasında diş çekiminin tedavi sürecini etkilemediğini bildiren Russell ve ark (2013) çalışma sonuçlarından farklılık gösterirken ${ }^{13}$, diğer çalışma sonuçları ile uyumludur. ${ }^{14}$ Leon-Salazar ve $\operatorname{ark}^{15}$ diş çekiminin tedavi süresini arttırdığını ve ek olarak tedavi etkinliğini negatif etkilediğini bildirmişlerdir. 
Çalışmamızda, her birey için tedavi sonrasında ortalama kök rezorbsiyon skoru varlığı panoramik radyografları ile değerlendirilmiştir. Panoramik radyografın avantajı tek görüntüde her iki çenenin ve tüm dişlerin izlenebilmesidir. ${ }^{10}$ Tüm populasyon için cinsiyetler arası fark gözlenmezken $(p=0,095)$, diş çekimi yapılan bireylerdeki ortalama kök rezorbsiyon skorunun anlamlı olarak yüksek olduğu görülmüştür $(p<0,05)$. Konuyla ilgili önceki çalışmalar da, bizim çalışmamıza benzer olarak, diş çekim prosedürünün kök rezorbsiyonu için önemli bir faktör olduğunu bildirmiştir. ${ }^{16-19}$ Sameshima ve Sinclair çalışmalarında (2001), özellikle en fazla kök rezorbsiyonunun ortodontik amaçla 4 premolar dişi çekilen bireylerde görüldüğünü, diş çekimi yapılmaksızın uygulanan ortodontik tedavilerde kök rezorbsiyonunun daha az olduğunu ve diş çekiminin rezorbsiyon açııından risk faktörü olduğunu belirtmişlerdir. ${ }^{19}$

Bizim çalışmamızda, diş çekimi yapılan ve yapılmayan gruplar arasındaki kök rezorbsiyon miktarları lokasyona göre değerlendirildiğinde, çekim yapilan bireylerde her sahada rezorbsiyon daha fazla olduğu halde yalnızca maksiller posterior sahadaki fark anlamlı bulunmuştur $(p<0,05)$. Bu farklılıkta yaş, cinsiyet, tedavi süresi gibi diğer faktörlerin etkili olabileceğini düşünmekteyiz.

Ortodontik sabit tedavinin plak retansiyonu ve gelişimi ile ilişkili olduğu bilinmektedir. ${ }^{20}$ Plak varlığı, periodontal hastalığa zemin hazırlanması ve gingival enflamasyon gelişiminde rol oynar. Aynı zamanda, yumuşak dokuda biyolojik hasara ve azalmış estetik sonuçlara neden olduğu gibi diş yüzeyinde de demineralizasyon ve çürük oluşumu açısından kritik öneme sahiptir. Ortodontik tedavi gören bireylerde beyaz lezyon oluşumunun arttığı pek çok çalışma ile gösterilmiştir. ${ }^{21-25}$

Bizim çalışmamızda, sabit ortodontik tedavi sonrası plak düzeyi ve gingival enflamasyon seviyesi, başlangıç değerlerine göre artı̧̧ göstermiştir. Bu sonuç, pek çok çalışma ile uyumludur. ${ }^{26,27,28}$ Liu ve ark. (2011), ortodontik tedavinin başlamasından kısa süre sonra plak akümülasyonunun ve gingival enflamasyonun arttığını, plak indeks ve gingival indeks skorlarının anlamlı artış gösterdiğini bildirmişlerdir. ${ }^{28}$ Benzer şekilde, Boke ve arkadaşları da (2014), sabit ortodontik tedavi gören hastalarda tedavi sonrası gingival enflamasyon ve plak düzeyinin arttığını bildirmişlerdir. ${ }^{28}$ Farklı olarak Davis ve ark (1991), ortodontik tedavi gören çocuklarda oral hijyen düzeyinin iyileştiğini bunun ortodontik tedaviye bağı olarak sık dişhekimi ziyaretinden kaynaklandığını bildirmişlerdir. ${ }^{29}$ Farkı görüşler olmakla birlikte, çocukluk ve puberte döneminde hormonal değişikliklere bağlı olarak gingival enflamasyon düzeyinin artması beklenen bir durumdur. ${ }^{30} \mathrm{Bu}$ çalışmada, gingival indeks skorları tedavi sonrasında artmıştır ancak diş çekimi yapılan bireylerdeki artı̧̧ dışında, diğer gruplarda bu fark anlamlı bulunmamışır. Bu durum, çalışmanın örneklem hacminin yeterli olmamasından kaynaklanıyor olabilir.

Çalışma sonuçlarımıza göre; ortodontik apareylerin, plak tutulumu açısından ek yüzey alanı oluşturmasının ve mekanik temizliğin etkin yapılmasında risk faktörü olmasının, plak ve gingival indekslerdeki artışa neden olduğu söylenebilir. Konuyla ilgili yapılmış uzun dönem bir çalışmada, ortodontik tedavinin bitirilmesini takiben ileri zamanda periodontal sağlığın iyileştiği, sondlamada kanama, plak indeks ve cep derinliğinin azaldığı bildirilmiştir. ${ }^{31}$ Ortodontik düzensizliklerin elimine edilmesi oral hijyenin sağlanması açısından önemlidir. Klinik parametrelerin ölçüm zamanı elde edilen sonuçlar üzerinde önemli etkiye sahiptir. Bizim çalışmamızda, tedavi sonrası değerlendirilen klinik fotoğraflar, ortodontik apareylerin çıkarılmasını takiben alınmıştır. Daha kesin bilgiler elde edebilmek için, ileri zamanlı kayıtların da alınması faydalı olabilir. Ancak, bizim hastalarımız pekiştirme tedavisine geçeceği ve uygulanacak hareketli apareylerin oral hijyen ve periodontal sağlık üzerine olası etkilerini elimine etmek için tüm kayıtlar sabit tedavi bitiminde, pekiştirme tedavisi öncesinde değerlendirildi.

\section{SONUÇ}

Çalışma popülasyonumuz için cinsiyet kök rezorbsiyonu üzerinde etkili değilken, diş çekimi kök rezorbsiyonunu arttırmışır. Aynı zamanda, ortodontik amaçla diş çekimi yapılan bireylerin tedavi süresi artmıştır. Uzun dönemde, dental sağığın idamesi açısından ortodontik amaçla yapılan uygulamaların ve ortodontik kuvvetlerin dişler üzerindeki olası etkileri göz ardı edilmemelidir.

Ortodontik tedavi esnasında, oral hijyen seviyesinde azalma ve gingival enflamasyonda artı̧̧ söz konusudur. Bu nedenle, tedavi sürecinde gingival

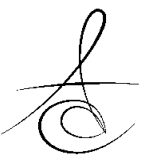


sağlığın korunması açısından, hasta, ortodontist ve periodontistin iletişimi önemlidir. Multidisipliner yaklaşımla, ev bakımına gerekli önemin verilmesi ve oral hijyen uygulamalarında optimal şartların sağlanması tedavinin başarısı açısından faydalı olacaktır

\section{KAYNAKLAR}

1- Shivakumar K, Chandu G, Shafiulla M. Severity of malocclusion and orthodontic treatment needs among 12-to 15-year-old school children of Davangere District, Karnataka, India. Eur J Dent 2010; 4: 298-307.

2- Bishara SE, Staley RN. Maxillary expansion: clinical implications. Am J Orthod Dentofacial Orthop 1987, 91: 3-14.

3- Grieve WG, Johnson GK, Moore RN, Reinhardt RA, DuBois LM. Prostaglandin E (PGE) and interleukin1 beta (IL-1 beta) levels in the gingival crevicular fluid during human orthodontic tooth movement. Am J Orthod Dentofacial Orthop 1994; 105: 36974.

4- Ousehal L, Lazrak L, Es-Said R, Hamdoune $H$, Elquars $F$, Khadija A. Evaluation of dental plaque control in patients wearing fixed orthodontic appliances: a clinical study. Int Orthod 2011; 9: 140-55.

5- Mummolo S, Marchetti E, Albani F, Campanella V, Pugliese F, Di Martino S, Tecco S, Marzo G. Comparison between rapid and slow palatal expansion: evaluation of selected periodontal indices. Head \& Face Med 2014; 15; 10:30.

6- Brezniak N. Orthodontically induced inflammatory root resorption. Part II: The clinical aspects. Angle Orthod 2002; 72: 180-4.

7- Hartsfield J. Genetic factors in external apical root resorption and orthodontic treatment. Crit Rev Oral Biol Med 2004; 15: 115-22.

8- Kristina Lopatiene, Aiste Dumbravaite. Risk factors of root resorption after orthodontic treatment. Stomatologija, Baltic Dental and Maxillofacial Journal 2008; 10: 89-95.

9- Sharpe W, Reed B, Subtelny JD, Polson A. Orthodontic relapse, apical root resorption, and crestal alveolar bone levels. American Journal of Orthodontics and Dentofacial Orthopedics 1987; 91: $252-8$
10-Jiang RP, McDonald JP, Fu MK. Root resorption before and after orthodontic treatment: a clinical study of contributory factors. Eur J Orthod 2010; 32: 693-7.

11- Kelly A, Antonio AG, Maia LC, Luiz RR, Vianna RBC, Quintanilha LELP. Reliability assessment of a plaque scoring index using photographs. Methods of Information in Medicine 2008; 47: 443-47.

12- Smith RN, Lath DL, Rawlinson A, Karmo M, Brook $A H$. Gingival inflammation assessment by image analysis: measurement and validation. Int J Dent Hyg 2008; 6: 137-42.

13-Russell B, Skvara M, Draper E, Proffit WR,Philips C, White RP. The association between orthodontic treatment with removal of premolars and the angulation of developing mandibular third molars over time. Angle Orthod. 2013; 83: 376-80.

14-Turbill EA, Richmond S, Wright JL. The time-factor in orthodontics: what influences the duration of treatments in National Health Service practices? Community Dent Oral Epidemiol 2001; 29: 62-72.

15-Leon-Salazar R, Janson G, Henriques JF, LeonSalazar V. Influence of initial occlusal severity on time and efficiency of Class I malocclusion treatment carried out with and without premolar extractions. Dental Press J Orthod 2014; 19: 3849.

16-McFadden WM, Engstrom $\mathrm{C}$, Engstrom $\mathrm{H}$, Anholm JM. A study of the relationship between incisor intrusion and root shortening. Am J Orthod Dentofacial Orthop 1989; 96: 390-6.

17-Baumrind S, Korn EL, Boyd RL. Apical root resorption in orthodontically treated adults. Am J Orthod Dentofacial Orthop 1996; 110: 311-323.

18-Sameshima GT, Sinclair PM. Predicting and preventing root resorption Part 1: diagnostic factors. Am J Orthod Dentofacial Orthop 2001; 119: 505-10.

19-Sameshima GT, Sinclair PM. Predicting and preventing root resorption Part 2: treatment factors. Am J Orthod Dentofacial Orthop 2001; 119: 511-5.

20-Migliorati M, Isaia $L$, Cassaro A, Rivetti A, Silvestrini-Biavati $F$, Gastaldo $L$, Piccardo I, Dalessandri D, Silvestrini-Biavati A. Efficacy of professional hygiene and prophylaxis on preventing plaque increase in orthodontic patients

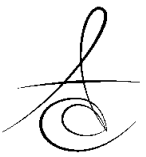


with multibracket appliances: a systematic review. Eur J Orthod 2015; 37: 297-307.

21-Ogaard B. Prevalence of white spot lesions in 19year-olds: a study on untreated and orthodontically treated persons 5 years after treatment. Am J Orthod Dentofacial Orthop 1989; 96: 423-7.

22- Mitchell L. Decalcification during orthodontic treatment with fixed appliances-an overview. $\mathrm{Br}$ J Orthod 1992; 19: 199-205.

23-Geiger AM, Gorelick L, Gwinnett AJ, Griswold PG. The effect of a fluoride program on white spot formation during orthodontic treatment. Am J Orthod Dentofacial Orthop 1998; 93: 29-37.

24-Banks PA, Chadwick SM, Asher-McDade C, Wright $\mathrm{JL}$. Fluoride-releasing elastomerics-a prospective controlled clinical trial. Eur J Orthod 2000; 22: 401-7.

25- Øgaard B, Larsson E, Henriksson T, Birkhed D, Bishara SE. Effects of combined application of antimicrobial and fluoride varnishes in orthodontic patients. Am J Orthod Dentofacial Orthop 2001; 120: 28-35.

26-Zachrisson BU, Zachrisson S. Gingival condition associated with partial orthodontic treatment. Acta Odontol Scand 1972; 30: 127-36.

27-Liu H, Sun J, Dong Y, Lu H, Zhou H, Hansen BF, Song $\mathrm{X}$. Periodontal health and relative quantity of subgingival Porphyromonas gingivalis during orthodontic treatment. Angle Orthod 2011; 81: 609-15.

28-Boke F, Gazioglu C, Akkaya S, Akkaya M. Relationship between orthodontic treatment and gingival health: A retrospective study. Eur J Dent 2014; 8: 373-80.

29-Davies TM, Shaw WC, Worthington HV, Addy M, Dummer $\mathrm{P}$, Kingdon $A$. The effect of orthodontic treatment on plaque and gingivitis. Am J Orthod Dentofacial Orthop 1991; 99: 155-61.

30-Mombelli A, Gusberti FA, van Oosten MA, Lang NP. Gingival health and gingivitis development during puberty. A 4-year longitudinal study. J Clin Periodontol 1989; 16: 451-6.

31-Sallum EJ, Nouer DF, Klein MI, Gonçalves RB, Machion L, Wilson Sallum A, et al. Clinical and microbiologic changes after removal of orthodontic appliances. Am J Orthod Dentofacial Orthop 2004; 126: 363-6.

\author{
Yazışma Adresi: \\ Dt. Aysel Ufuk Şenol \\ Ankara Üniversitesi \\ Dişhekimliği Fakültesi \\ Periodontoloji Anabilim Dalı \\ 06500 Beşevler/ Ankara \\ Tel: 90-536 4858283 \\ E-mail: senol.ufukk@gmail.com
}

